\title{
Automatic Control of Drip Irrigation System \& Monitoring Of Soil by Wireless
}

\author{
Aniket H. Hade, Dr. M.K. Sengupta \\ ( Department of EEE, PRMCEAM, Badnera, SGBA University, India )
}

\begin{abstract}
In past couple of decades, there is immediate growth in field of agricultural technology. Utilization of proper method of irrigation by drip is very reasonable and proficient. A various drip irrigation methods have been proposed, but they have been found to be very luxurious and dense to use. The farmer has to maintain watch on irrigation schedule in the conventional drip irrigation system, which is different for different types of crops. In remotely monitored embedded system for irrigation purposes have become a new essential for farmer to accumulate his energy, time and money and will take place only when there will be requirement of water. In this approach, the soil test for chemical constituents, water content, and salinity and fertilizer requirement data collected by wireless and processed for better drip irrigation plan. This paper reviews different monitoring systems and proposes an automatic monitoring system model using Wireless Sensor Network (WSN) which helps the farmer to improve the yield.
\end{abstract}

Keywords: Drip irrigation, Data logger, Fertilizer, Hotspot, Multiplexer, Remote monitoring, Soil, sensors, ZigBee.

\section{Introduction}

The Irrigation is the artificial application of water to the soil for assisting in growing crops. Drip irrigation also known as micro irrigation \& is an irrigation method which minimizes the use of water $\&$ fertilizer by allowing water to drip slowly to the roots of plants, either onto the soil surface or directly onto the root zone due to which a large quantity of water is saved $\&$ also the fertilizer which comes to the plant with the water. Indian agriculture is dependent on the monsoons, which is dependent on the nature and not a reliable source of water, so there is a need for an automatic irrigation system in the country which can provide water to the farms according to their moisture, temperature and soil types \& fertilizers. For a big farm land with horticulture activity the solution will be an automated system. Water contained in the soil is called soil moisture. And it is very important for plant growth. Water soluble fertilizer can be also applied without any wastage by this drip irrigation system. The advantage of using wireless sensors is to control all related parameters for better irrigation management.

This paper gives a review of remote monitoring and control system based on existing technologies. ZigBee or Hotspot based remote control and monitoring system with automatic irrigation management is proposed in this project. The rest of the paper is organized as follows. Section II summarizes the literature review on the existing systems. Section III analyzes the main aim and prime objective of the automatic irrigation system. Section IV describes the basic need of the project. Section V describes the proposed system. Finally, Section $\mathrm{V}$ deals with conclusion and future scope. And the last is the reference papers and publications.

\section{Literature Review}

After the research in the agricultural field, researchers found that the yield of agriculture goes on decreasing day by day. Use of technology in the field of agriculture plays important role in increasing the production as well as in reducing the extra man power efforts, water requirement and fertilizer requirement. Some of the researchers tried for betterment of farmers and provides the systems that use technologies which are helpful for increasing the agricultural yield. Some of such researches carried out in the field of agriculture are summarized below.

In Turkey, $75 \%$ of the current fresh water is consumed in the agricultural irrigation [11]. Therefore, efficient water management plays an important role in the irrigated agricultural cropping systems [16],[28]. In order to produce "more crop per drop", growers in (semi) arid regions are currently exploring irrigation techniques in the range from using less fresh water [3],[24]. One of them is making agriculture in a manner of sense, which uses a different type of sensors [19]. A site-specific wireless sensor-based irrigation control system is a potential solution to optimize yields and maximize water use efficiency for fields with variation in water availability due to different soil characteristics or crop water needs and site-specific controlling irrigation valves [17],[3],[7]. Decision making process with the controls is a viable option for determining when and where to irrigate, and how much water to use. Temporal monitoring of soil moisture at different growth stages 
of the crop could prevent water stress and improve the crop yield [10],[5]. Sensor-based irrigation systems have been studied in many applications [15],[21],[30],[31],[38],[1],[17],[18].

In the last two decades, with the development of wireless technologies, several researches focused on autonomous irrigation with sensors in agricultural systems [25], [39]. Amongst these works, a micro sprinkler system has a different place, and it was designed for latching the controlled solenoid valves in a citrus orchard with wireless sensors [33]. Afterwards, soil moisture sensors and sprinkler valve controllers are being used for site-specific irrigation automation [16],[22],[36],[27],[9]. The advantages of using wireless sensors are having the reduced wiring and piping costs, and easier installation and maintenance in large areas [26],[37],[2]. After the usage of wireless technology began in agricultural irrigation, a trial was made to involve different types of equipments in such instrumentations. In terms of controllers,[22],[7],[8] were designed microcontroller sitespecific irrigation, wireless monitoring system was implemented with a field programmable gate array (FPGA) by [20].

In terms of protocols, infra-red, GSM/GPRS WPANs (Wireless Personal Area Networks), Bluetooth, WLANs (Wireless Local Area Networks) have been put to different utilities to implement wireless sensors in precision agriculture [37],[4],[35],[29]. Many studies have successfully demonstrated the use of active and passive microwave remote sensing too [13],[34],[14]. It has been seen that many irrigation scheduling methods by wireless sensors have been developed for the last several decades. Many of the commercially available sensors, valves and modules assembled for irrigation system networks are too complex and/or costly to be feasible for site-specific management of fixed irrigation systems. The adoption of them by producers has been limited due to cost, installation time, maintenance, and complexity of systems [32], [23].

\subsection{Aim}

\section{Aim \& Objectiv E}

The main aim of the research is to develop and to test an automation system having a low cost equipment and feedback type controller for site-specific management of irrigation systems and also to have a alternative power source like solar power or wind power. The data available from the various sensors will be received at the wireless base station for proper control, based on data.

\subsection{Objective}

The prime objective is to select the appropriate wireless network to collect the data from moisture sensors, water soluble fertilizer sensor placed in the field, temperature sensors of various areas of the field, pressure sensors in the irrigation system to monitor the proper drip of water along with the fertilizer which are kept in a separate tank.

Another addition of the proposed automation system is to install the digital cameras to monitor the plant growth and overall condition of the field. In addition, the developed irrigation method partly removes the excess workload of the farmers.

To identify the suitable pump with facility for maintaining certain recommended pressure in the water pipe. To indentify proper sensors and monitoring device required for the farming data like soil moisture, soil temperature, soil fertilizer \& chemical constituents.

Search of appropriate sensors with specifications and coordinating wireless system for acquisition of various data. To process the data based on the limits set and there by controlling the whole irrigation management. To find the economic method of drip irrigation and its technique for automation regarding short term and long term crop.

\section{Need Of The Project}

In India, the market is mainly based on agriculture and the climatic environment is isotropic and is not able to make full use of agricultural assets. The main cause is the lack of rains in many part of India and scarify of land water. The demand for new water saving techniques in irrigation is growing immediately right now. At the present period, the farmers have been using irrigation technique in India through the manual control in which the farmers irrigate the land at the normal interval. This process sometimes consumes additional water or sometimes the water reaches delayed due to which the crops get dehydrated. The effectiveness of the irrigation is determined by a number of different factors, including the type of irrigation system and the conditions at its instance of application.

Irrigation is the artificial application of water to the soil usually for supporting in harvesting the crops. In crop production, it is mainly used in desiccated area and in periods of rain water shortfalls.

Types of Irrigation:

Surface Irrigation: Surface irrigation is defined as the group of application techniques where water is applied and distributed over the soil surface by gravity. It is by far the most common form of irrigation throughout the 
world. Surface irrigation is often referred to as flood irrigation, use of canals, rivers, ponds, deep tube well are seen in surface irrigation

Drip Irrigation: Drip irrigation, also known as trickle irrigation or micro irrigation or localized irrigation, is an irrigation method which saves water and fertilizer by allowing water to drip slowly to the roots of plants, either onto the soil surface or directly onto the root zone, through a network of valves, pipes, tubing, and emitter[40].

\section{Proposed System}

The betterment of agriculture depends on various environmental parameters such as soil temperature, soil moisture, relative humidity, $\mathrm{pH}$ of soil, light intensity, fertilizing property of the soil, etc. Any small changes in any of these parameters can cause problems like diseases, improper growth of plant, etc. mainly resulting in lesser yield.

The block diagram of the proposed system of input unit is shown in Fig. 1 consists of different types of sensing unit such as Soil Moisture Sensor to measure water content of soil, Temperature Sensor detects the temperature, Humidity Sensor to measure the presence of water in air, Pressure Regulator Sensor to be selected for maintaining the recommended pressure, Molecular Sensor selected for better crop growth, Digital Camera with capability of tracking and taking photographs of the crop field to find the crop growth for measurement. The output of sensors are converted to analog using D/A converter at the transmitter input side and converted back to digital using A/D converter at the receiver output side. Multiplexer sometimes called Data selector is a combinational logic circuit that selects one of $2 n$ inputs and route it to the output. The data obtained from different types of sensors are transmitted to the Multiplexer using Wireless Sensor Network. ZigBee or Hotspot modules for wireless data transfer and receiving for control unit.

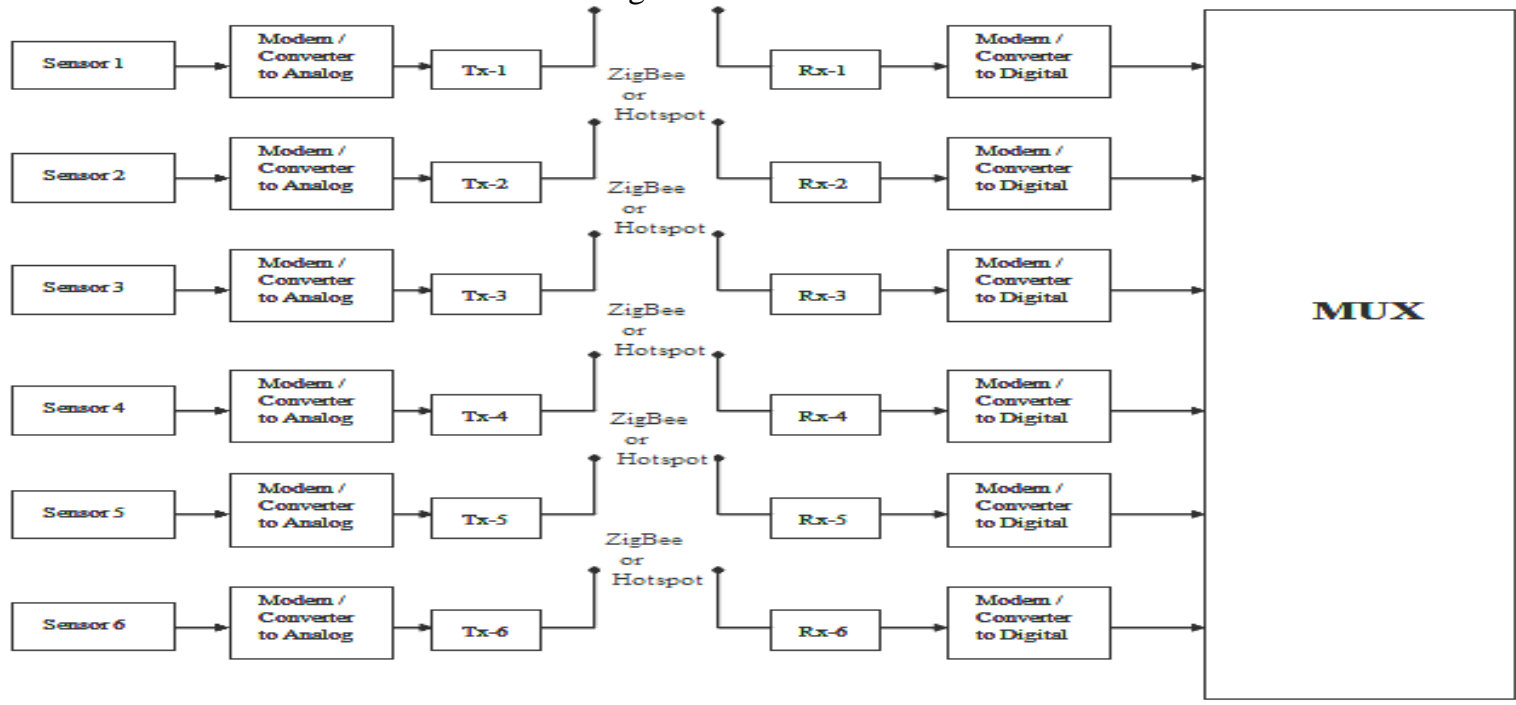

Fig. 1 Basic block diagram of proposed system (input part)

The block diagram of the proposed system of control unit is shown in Fig. 2 consists of data logger which allows count information to be associated with the date and time, and for the data to be downloaded onto a PC for flexible and detailed data analysis, Demultiplexer split a combined stream arriving from a shared medium into the original information streams and fed to different types of actuators such as drip irrigation pump, boring pump, fertilizer pump, controlling of pump speed, controlling of fertilizer input from the tank and display the field etc. 


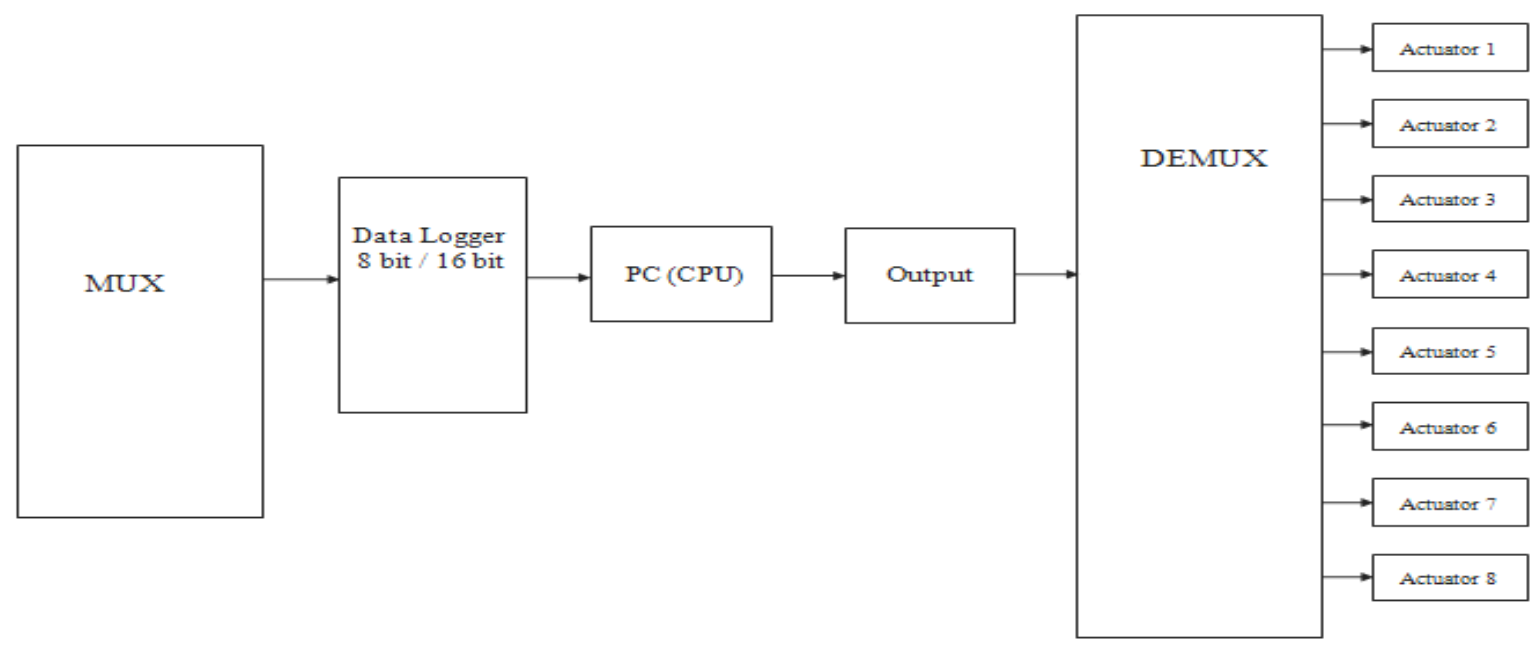

Fig. 2 Basic block diagram of proposed system (control unit)

\section{Conclusions \& Future scope}

It can be concluded that the modern use of electronic, electrical, chemical and mechanical systems will be very advantages for better agricultural output. Preservation of water sources and minimizing the use of inorganic fertilizer are possible with these methods. Use of bio-fertilizer in appropriate manner will find better guiding parameters through the various sensing methods. In this age of population explosion the huge demand of food can be met with this state of the art process.

To keep the environmental balance of various sources of this planet and maintaining the methane generation during harvesting under control, this modern approach will help to reach a target with more modern gadgets. In future days to come, we can even apply food nutrients to the plant and crop by air mixed with very less water, with better monitoring and processing.

\section{References}

[1]. Abreu VM, Pereira LS (2002). Sprinkler irrigation systems design using ISAMim. p. 022254.

[2]. Baggio A (2005). Wireless sensor networks in precision agriculture. In: On-line Proc, of the Workshop on Real-World Wireless Sensor Networks, pp. 50-51.

[3]. Balendonck J, Hemming J, Van Tuijl BAJ, Pardossi A, Incrocci L, Marzialetti P (2008). Sensors and Wireless Sensor Networks for Irrigation Management under Deficit Conditions (FLOW-AID). International Conference on Agricultural Engineering (AgEng2008). Conf. Proc. p.19.

[4]. Camilli A, Cugnasca CE, Saraiva AM, Hirakawa AR, Corrêa LP (2007). From wireless sensor to field mapping: Anatomy of an application for precision agriculture. Comput. Electron. Agric., 58: 25-36

[5]. Coates RW, Delwiche M, Brown P (2005). Precision Irrigation in Orchards: Development of a Spatially Variable Micro sprinkler System. Information and Technology for Sustainable Fruit and Vegetable Production (FRUTIC). pp. 611-624.

[6]. Coates RW, Delwiche MJ (2006). Solar-Powered, Wirelessly-Networked Valves for Site- Specific Irrigation. ASABE Annual International Meeting. Paper, pp. 062165

[7]. Coates RW, Delwiche MJ, Brown PH (2006a). Control of individual micro sprinklers and fault detection strategies. Precision Agric.,7: 85-99.

[8]. Coates RW, Delwiche MJ, Brown PH (2006b). Design of a system for individual micro sprinkler control. Trans. ASABE, 49(6): 1963-1970.

[9]. Damas M, Prados AM, Gomez F, Olivares G (2001). HidroBus® system: fieldbus for integrated management of extensive areas of irrigated land. Microprocessors Microsyst. 25: 177-184.

[10]. Doraiswamy PC, Hatfield JL, Jackson TJ, Akhmedov B, Prueger J, Stern A (2004). Crop condition and yield simulations using Landsat and MODIS. Remote Sensing Environ., 92: 548-559.

[11]. Dursun M, Ozden S (2010). A Prototype of PC Based Remote Control of Irrigation. International Conference on Environmental Engineering and Application (ICEEA), pp. 255-258. (IEEE Catalog Number: CFP1020L-PRT)

[12]. Dursun M, Ozden S (2011). Application of Solar Powered Automatic Water Pumping in Turkey. International Conference on Electrical Energy and Networks (ICEEN), pp. 52-57. (IEEE Catalog Number: CFP1155M-PRT)

[13]. Engman ET, Chauhan N (1995). Status of microwave soil moisture measurements with remote sensing. Remote Sensing Environ., 51: 189-198.

[14]. Jackson TJ, Vine DL, Hsu AY, Oldak A, Starks P, Swift C, Isham J, Haken M (1999). Soil moisture mapping at regional scales using microwave radiometry: the Southern Great Plains Hydrology Experiment. IEEE Trans. Geosci. Remote Sensing, 37:21362151 .

[15]. Jacobson BK, Jones PH, Jones JW, Paramore JA (1989). Real-time greenhouse monitoring and control with an expert system. Comput. Electron. Agric., 3: 273-285.

[16]. Kim Y, Evans RG (2009). Software design for wireless sensor-based site-specific irrigation. Comput. Electron. Agric., 66: 159-165

[17]. Kim Y, Evans RG, Iversen WM (2008). Remote sensing and control of an irrigation system using a distributed wireless sensor network. IEEE Trans. Instrum. Meas., 57(7): 1379-1387.

[18]. Kim Y, Evans RG, Iversen WM (2009). Evaluation of closed-loop site-specific irrigation with wireless sensor network. J. Irrig. Drain. Eng., 135(1): 25-31. 
[19]. Lopez RJA, Sotoa F, Suardiaza F, Sancheza P, Iborraa A, Verab JA (2009). "Wireless Sensor Networks for precision horticulture in Southern Spain". Comput. Electron. Agric., 68: 25-35.

[20]. Mendoza-Jasso J, Vargas GO, Miranda RC, Ramos EV, Garrido AZ, Ruiz GH (2005). FPGA-based real-time remote monitoring system. Comput. Electron. Agric., 49: 272-285.

[21]. Meron M, Assaf R, Bravdo B, Wallach R, Hallel R, Levin A, Dahan I (1995). Soil sensor actuated microirrigation of apples. In: Proceedings of the 5th International Microirrigation Congress, ASABE. pp. 486-491.

[22]. Miranda FR, Yoder R, Wilkerson JB (2003). A site-specific irrigation control system. ASAE Annual International Meeting. p. 031129.

[23]. Miranda FR, Yoder RE, Wilkerson JB, Odhiamboc LO (2005). An autonomous controller for site-specific management of fixed irrigation systems. Comput. Electron. Agric., 48:183-197.

[24]. Ngaira JKW (2007). Impact of climate change on agriculture in Africa by 2030. Sci. Res. Essays, 2(7): 238-243.

[25]. Oksanen T, Ohman M, Miettinen M, Visala A (2004). Open configurable control system for precision farming. Automation Technology for Off-Road Equipment, Proceedings, 701P1004.

[26]. Panchard J, Rao S, Prabhakar TV, Jamadagni HS, Hubaux JP (2006). COMMON-Sense Net: Improved Water Management for Resource-Poor Farmers via Sensor Networks. ICTD 2006 Conference.

[27]. Perry CD, Dukes MD, Harrison KA (2004). Effects of variable-rate sprinkler cycling on irrigation uniformity. ASAE Annual International Meeting, p. 041117.

[28]. Sezen SM, Celikel G, Yazar A, Tekin S, Kapur B (2010). Effect of irrigation management on yield and quality of tomatoes grown in different soilless media in a glasshouse. Sci. Res. Essay, 5(1): 41-48.

[29]. Siuli Roy AD, Bandyopadhyays S (2008). Agro-sense: Precision agriculture using sensor-based wireless mesh networks. Innovations in NGN: Future Network and Services. In: Proceedings of the First ITU-T Kaleidoscope Academic Conference (KINGN 2008). pp. 383-388.

[30]. Stone KC, Smajstrla AG, Zazueta FS (1985). Microcomputer-based data acquisition system for continuous soil water potential measurements. Soil Crop Sci. Soc. Fla. Proc., 44: 49-53.

[31]. Testezlaf R, Zazueta FS, Yeager TH (1997). A real-time irrigation control system for greenhouses. Appl. Eng. Agric., 13 (3): 329332 .

[32]. Thelen J, Goense D, Langendoen K (2005). Radio wave propagation in potato fields. In: First Workshop on Wireless Network Measurements (co-located with WiOpt2005), pp. 1-4.

[33]. Torre-Neto A, Schueller JK, Haman DZ (2000). Networked sensing and valve actuation for spatially-variable microsprinkler irrigation. ASAE Annual International Meeting. pp. 001158

[34]. Ulaby FT, Dubois PC, Zyl JJV (1996). Radar mapping of surface soil moisture. J. Hydrol., 184: 57-84.

[35]. Vellidis G, Tucker M, Perry C, Kvien C, Bednarz C (2008). A real-time wireless smart sensor array for scheduling irrigation. Comput. Electron. Agric., 61: 44-50.

[36]. Wall RW, King BA (2004). Incorporating plug and play technology into measurement and control systems for irrigation management. ASAE Annual International Meeting. pp. 042189.

[37]. Wang N, Zhang N, Wang M (2006). Wireless sensors in agriculture and food industry - Recent development and future perspective. Comp. Electron. Agric., 50: 1-14.

[38]. Zazueta FS, Smajstrla AG (1992). Microcomputer-based control of irrigation systems. Appl. Eng. Agric., 8(5): 593-596.

[39]. Zhang Z (2004). Investigation of wireless sensor networks for precision agriculture. ASAE Annual International Meeting. p. 041154

[40]. Manish Giri, Dnyaneshwar Natha Wavhal (2013).Automated Intelligent Wireless Drip Irrigation Using Linear Programming International Journal of Advanced Research in Computer Engineering \& Technology (IJARCET)Volume 2, Issue 1 